\section{Mindset, Motivation, and Teaching Practice: Psychology Applied to Understanding Teaching and Learning in STEM Disciplines}

\author{
Deborah South Richardson, ${ }^{\dagger *}$ Robert S. Bledsoe, ${ }^{*}$ and Zaraly Cortez ${ }^{\S}$ \\ ${ }^{\dagger}$ Department of Psychological Sciences and "Department of English and World Languages, \\ Augusta University, Augusta, GA 30912; 'Department of Psychology, Marshall University, \\ Huntington, WV 25755
}

\begin{abstract}
Psychological theories of motivation and performance are relevant to teaching and learning in the science, technology, engineering, and mathematics (STEM) disciplines. The present study applies Dweck's mindset theory of motivation to an examination of the relationship among instructor mindset, instructor motivational attitudes, and the use of effective teaching practices. Faculty members who teach undergraduate courses in STEM disciplines completed a survey designed to assess fixed versus growth mindset, mastery orientation (measures of motivation and efficacy), and teaching practices. Results supported a model consistent with Dweck's theory of motivation, whereby mastery orientation mediates the relationship between instructor mindset and teaching behaviors. It appears that this psychological theory of motivation may be helpful in understanding teaching and learning in STEM disciplines. More research using a variety of measures and teaching contexts is necessary before full applicability can be realized.
\end{abstract}

\section{INTRODUCTION}

Insights from psychological studies relating motivation and mindset to learning and persistence have received significant attention in attempts to improve science, technology, engineering, and mathematics (STEM) education (Grant and Dweck, 2003; Blackwell et al., 2007; Dweck, 2008). Dweck and Leggett (1988) described the social-cognitive approach to motivation and personality that underlies the research linking mindset to student learning. Their research attempted to explain why some students adopt a maladaptive "helpless" response of avoidance and poor performance in the face of challenge, whereas others adopt a mastery-oriented pattern that seeks challenge and sustains efforts in the face of failure. They argued that these behaviors result from how individuals conceptualize the goals of their pursuit. Those who are motivated by performance goals seek favorable evaluations of their competence; they want to appear smart or able. Those who are motivated by learning goals seek to actually become more competent and learn more.

\section{Implicit Theories}

In seeking an explanation for the development of performance or learning goals, Dweck and Leggett (1988) turned to the concept of implicit theories of self. They argued that individuals who view their intelligence as a fixed entity would be more likely to adopt performance goals, which would lead them to fear failure and avoid challenge. Those who view their intelligence as malleable would be more likely to adopt mastery goals and thus exert effort in the face of challenge. In sum, the individual's implicit theory about intelligence (i.e., mindset) affects goals in a learning situation (performance vs. mastery), which in turn impacts behavior (i.e., avoiding vs.
Kimberly Tanner, Monitoring Editor Submitted Nov 15, 2019; Revised Jun 16, 2020; Accepted Jun 29, 2020

CBE Life Sci Educ September 1, 2020 19:ar46 DOI:10.1187/cbe.19-11-0238

*Address correspondence to: Deborah South Richardson (derichardson@augusta.edu).

(c) 2020 D. S. Richardson et al. CBE-Life Sciences Education (๑) 2020 The American Society for Cell Biology. This article is distributed by The American Society for Cell Biology under license from the author(s). It is available to the public under an Attribution-Noncommercial-Share Alike 3.0 Unported Creative Commons License (http://creativecommons.org/licenses/ by-nc-sa/3.0)

"ASCB®" and "The American Society for Cell Biology $\circledR^{\prime \prime}$ are registered trademarks of The American Society for Cell Biology. 
facing challenge). These theories of intelligence are often referred to as fixed mindset and growth mindset.

\section{Mindset and Student Outcomes}

Dweck's model of implicit theories of intelligence has been applied extensively to explain student learning strategies and student success, and interventions based on the model have been used to improve student academic outcomes. Grant and Dweck (2003), for example, found that growth mindset, evidenced by an orientation toward learning goals, was related to deeper learning strategies and higher grades in an organic chemistry course. Students with a fixed mindset failed to recover from an initial poor grade. Blackwell et al. (2007) found that, with the challenge of transition to seventh grade, students with an incremental (i.e., growth) mindset improved math grades over 2 years. In a study examining the effect of a mindset intervention with seventh graders from a different school, they found that students who had participated in a series of workshops that included a mindset intervention did not show the typical declining grade trajectory that was evidenced among students in the control group.

Other attempts to employ mindset interventions have been effective in improving student achievement. Several researchers have employed online mindset interventions as a means of efficiently impacting a large number of students (Paunesku et al., 2015; Yeager et al., 2016). These intervention studies revealed more change toward growth mindset among students who had experienced the intervention than among those in the control group, as well as improved grades for previously lowest-performing (i.e., at-risk) students.

Burnette et al. (2013) conducted a meta-analytic review of implicit theories and reported a positive relationship of incremental beliefs (growth mindset) with learning goals and mastery orientation. They also reported that incremental beliefs were negatively associated with performance goals and helpless strategies (i.e. avoiding challenge). Thus, this meta-analysis provided support for Dweck's model, demonstrating expected relationships of mindset with goals and outcomes.

Several recent studies have questioned the mindset construct and the predictive ability of that construct. Meta-analyses by Sisk and colleagues (2018) suggested that the relationships predicted by the model are not as robust as the theory would anticipate. Cook et al. (2018) reported that fixed mindset did not show the expected relationship to performance goals in their study of measures of mindset and motivation. Burgoyne et al. (2020) designed a study to test six key premises of mindset theory. They found, at best, weak relationships that would be predicted by the model (e.g., people with growth mindsets hold learning goals) and concluded that other motivation constructs have demonstrated stronger relationships with presumed outcomes of mindset.

\section{Instructor Mindset}

Dweck and Leggett (1988) note that individuals' implicit theory not only affects their own goals and behaviors, but also may influence their view or expectations of others. Those with a fixed/entity theory about others' intelligence will make "oversimplified, all-or-nothing characterizations" of others and be less likely to pursue change. Those with an incremental/growth theory of others' intelligence are more likely to pursue develop- ment goals, seeking "improvement of valued attributes or mastery of valued tasks" (p. 268). Those individuals would take a mastery-oriented approach in the face of difficulty. Thus, we might anticipate that instructor mindset may be related to student outcomes.

Recent research has suggested that instructor mindset does impact student persistence and success. For example, Canning and colleagues (2019) found that the mindset of STEM professors is associated with student motivation and achievement. Students in classes taught by STEM faculty who believed the students' ability was fixed demonstrated overall poorer performance, and the difference in achievement between students of growth and fixed mindset instructors was larger for students from underrepresented minorities. Course evaluation data revealed that students reported less motivation to do their best work in classes of fixed mindset instructors. Students also reported that the fixed mindset instructors were less likely to use teaching practices that emphasize learning and development, and the students were less likely to recommend those instructors' courses to others. Canning et al. (2019) argue that "professors' beliefs about the nature of intelligence are likely to shape the way they structure their course, how they communicate with students, and how they encourage (or discourage) students' persistence. These malleable teaching practices have important implications for the motivation, learning, and achievement of all students in their classes" (p. 4).

\section{Instructor Beliefs and Teaching Practices}

Understanding the link between instructors' beliefs and their teaching practices may offer insights into factors that influence student achievement and may also lay the groundwork for attempts to encourage instructors to use effective teaching practices. Ferrare (2019) found a link between instructors' beliefs about learning and their teaching. Working from the perspective of Woodbury and Gess-Newsome's (2002) teacher-centered systemic reform model, which argues that "instructors' beliefs about teaching, learning, and content are inextricably linked to their classroom practices" (p. 2), this study examined the relationship of student-centered versus teacher-centered beliefs on teaching practices of STEM instructors. Through classroom observations in STEM gateway courses and interviews with faculty about what students should learn, what they should do to learn, and what instructors should do to aid student learning, Ferrare discovered distinct instructional styles that were linked to certain beliefs about student learning. For example, instructors who believed that student success was related to individual perseverance were likely to employ "chalk talks," in which they modeled problem solving through examples and demonstrations.

Similarly, Rattan et al. (2012) conducted four studies that examined how implicit theories of math intelligence relate to attributions for student performance and teaching strategies. They reported that entity/fixed mindset was associated with an expectation of poor student performance and use of teaching strategies that would likely reduce student engagement and achievement (e.g., consoling for poor performance, suggesting dropping the class). In a further examination of student response to such strategies, they found that students who received such feedback expected lower grades, felt less motivated, and considered the professor to be less engaged. 
In their search for individual differences among instructors that might affect their response to evidence-based teaching practices, Aragon et al. (2018) found that STEM instructors with a fixed mindset adopted fewer active-learning practices and were less convinced that those practices were a good idea. They suggested that initiatives aimed at encouraging the adoption of active-learning strategies should explicitly address theories of intelligence.

\section{Current Study}

The present study adapts Dweck's (2000) self-theory, in which individuals' mindsets about their own intelligence or ability affects goals and performance, to an implicit theory about others in which individuals' mindsets about the intelligence or ability of others relates to their beliefs about motivation. Specifically, this study considers how instructor beliefs as reflected in their implicit theory of intelligence relates to their mastery orientation (in terms of mastery goals for students, attitudes about student efficacy, their personal teaching efficacy) and, ultimately, their teaching behaviors. Our argument is that the mindset of college instructors who face the often challenging task of facilitating the learning of college students will be associated with their beliefs about learning and motivation and their approach to instruction. According to Dweck (2006), instructors who operate with an entity/ fixed theory of intelligence are likely to consider themselves to be "finished products," and their role as one of imparting knowledge. Those with an incremental/growth theory of intelligence would be expected to be more open to adopting goals and strategies that actively engage students in their learning.

In sum, this study examined the relationship of STEM instructor mindset to motivational goals and teaching practices. We aimed to test the hypothesis derived from Dweck's implicit theory of self that instructors with a more growth-oriented (incremental) mindset will be more likely to adopt mastery-oriented goals for themselves and for their students. In turn, those mastery-oriented instructors would be more likely to adopt evidence-based, effective teaching practices. Thus, as Dweck's theory would suggest, we tested a model whereby mastery orientation mediates the relationship between mindset and teaching behaviors. In view of recent arguments that motivation constructs other than mindset may be more strongly associated with achievement-related behaviors (Cook et al., 2018; Burgoyne et al., 2020), we were generally interested in the relative ability of mindset and mastery orientation to predict evidence-based teaching practice.

\section{METHODS}

\section{Participants}

Fifty-seven faculty members from five academic departments at a comprehensive research university in the southeast participated in the study. This public university with approximately 9000 students was created by the consolidation of an academic health center with a regional comprehensive university. It offers 150 undergraduate, graduate, and professional degrees from 10 colleges. This study examines the responses of 15 instructors from biological sciences, 15 from mathematics, 10 from chemistry, 10 from kinesiology, and 7 from physics.

\section{Measures}

The questionnaire consisted of items adapted from measures of mindset, motivations, and behaviors. All responses were made on six-point scales, ranging from 1 (strongly disagree) to 6 (strongly agree). Composite scores were created for each measure by averaging responses across items.

Instructor Mindset. Instructor mindset was assessed with a four-item version of Dweck's (2000) measure of growth/fixed mindset (Cook et al., 2018; e.g., "You have a certain amount of intelligence/ability and you really cannot do much to change it"). Consistent with previous literature, the scale evidenced strong internal consistency $(\alpha=0.88)$.

Instructor Mastery Orientation. We conceived of mastery orientation as a set of instructor attitudes about the probability that students can master the assigned work, which requires that the instructors believe students can meet learning expectations with appropriate effort, encourage students to exert effort to master the material, and believe that their own efforts can contribute to student mastery. We adapted 13 items from the Pattern of Adaptive Learning Scales (PALS; Midgley et al., 2000), which has been used extensively to assess achievement orientation in terms of performance and mastery goals (e.g., Cook et al., 2018). Internal consistency of this measure of Instructor Mastery Orientation was 0.65 (Cronbach's alpha). The adapted items reflect the adaptation of Dweck's self-theory to an implicit theory of motivation that considers the relationship of behaviors to beliefs about how to motivate others.

We modified some questions to address an instructor's belief that students are able to do the assigned work if they exert effort. For example, the original student item, "I'm certain I can master the skills taught in class this year," was modified to "I am confident that students can master the material taught in my classes." The other items aiming at this component of mastery orientation were: "I'm certain that students can figure out how to do the most difficult class work," "I'm certain that students can do almost all of the work in class if they don't give up," and "Even if it takes hard work, students can learn the material in my class."

We adapted items that had been designed to assess teachers' perceptions that the school sends a message to students that academic work is intended to help them develop competence by restating items to address the instructor's message rather than a message from the institution. Thus, responses to these items should reflect the instructor's intention to motivate students by encouraging them to exert effort. For example, the original PALS item "The importance of trying hard is really stressed to students" was modified to read "I stress the importance of trying hard to my students." The other items were: "I tell students that it's okay to make mistakes as long as they are learning and improving," "I emphasize really understanding the material, not just memorizing it," "I make an effort to recognize students for effort and improvement," and "I make an effort to show students how the work they do in my classes is related to their lives outside of school."

Assessment of instructor belief that their efforts can influence student mastery involved three items from the PALS and one item developed by the researchers. Items adapted from the PALS included: "If I try hard, I can get through to most of the 
students in my class," "Factors beyond my control have a greater influence on my student's achievement than I do" (reverse scored), and "Some students are not going to make progress, no matter what I do" (reverse scored). The additional item was "I design my courses to ensure that most students will learn.”

Teaching Behaviors. Our measure of teaching behaviors consisted of 23 items distributed between six types of evidence-based effective teaching practices: active learning (e.g., small group work), opportunities for practice and feedback (e.g., providing access to answer keys), transparent assignments (e.g., clear criteria for successful completion), reflective activities (e.g., ask students to reflect on learning), motivating activities (e.g., connecting course material to their lives), and reflective teaching (e.g., using student feedback to improve the course). All items are based on practices referenced in Wieman and Gilbert (2014) and included in the accompanying Teaching Practices Inventory (TPI). Items selected were relevant to a wide variety of teaching situations, including those in nonSTEM fields, so that the instrument could be evaluated for use in these fields as well. Items were excluded if they were not relevant to the teaching situation at our institution (such as the use of teaching assistants) or were assigned no point value on the TPI. We selected items with high point values on the TPI when possible.

We used Likert scales rather than the scoring system suggested by Wieman and Gilbert (2014) in order to maintain consistency with other items on the survey. For example, an item from the TPI asking the fraction of a typical class period the instructor spends lecturing received a high score if the instructor indicated that he or she spends less than $60 \%$ of the time lecturing. Our adapted item asked instructors to report the extent to which they agreed that the fraction of typical class time spent lecturing is less than 60\%. The complete set of items for assessment of teaching behaviors appears in Appendix A in the Supplemental Material.

Respondents were instructed to think about an undergraduate course that they taught last semester or were teaching during the current semester. If they taught more than one, they were asked to think about the course that was most challenging for their students. Respondents indicated the extent to which they agreed that they engage in each of the 23 practices. Internal consistency (Cronbach's alpha) was 0.80 .

\section{Validity of Measures}

With the exception of the Mindset items, our measures had not been used in the present form in previous investigations. Although validity of measurement must be established in each context (Downing, 2003; Reeves and Marbach-Ad, 2016), we often rely on previously established validity to determine the interpretability of a measure. In this study, only the measure of Mindset had evidence of validity from previous research.

There are several forms of validity evidence as articulated in the Standards for Educational and Psychological Testing (American Educational Research Association et al., 2014). Our measure of Teaching Behavior met several of the criteria for establishing the validity of inference in our study. Internal consistency met the accepted standard, demonstrating internal structure validity. Evidence of content validity derives from the fact that extensive research provides evidence that the teaching practices included in our measure are effective (Wieman and Gilbert, 2014) and from the attempt on the part of the investigators to tie the items to particular evidence-based practices. Validity evidenced by (predicted) relationships to other variables will be demonstrated by support for the predicted model.

Content validity of our measure of Mastery Orientation is demonstrated by the selection of content based on theories of motivation and the fact that our items were derived from a measure based on motivation theory and defined the domain of mastery motivation. Support for our hypotheses in the present study will attest to the validity of the measure in terms of its relationship to other variables. Although internal consistency only approached $(\alpha=0.65)$ the standard for assuring internal structure validity ( $\alpha=0.70$ ), we are not especially concerned, because weak internal consistency actually decreases the probability of finding predicted relationships among variables (Henson, 2001; Furr, 2017).

In addition to the previously established validity of the measure of Mindset, we offer evidence of validity in this context in terms of internal consistency, consistency of content with the underlying theory, and predicted relationships with other variables in the study.

\section{Procedures}

Chairs of academic departments with undergraduate programs at the university agreed to allow a researcher (D.S.R., R.S.B., and Z.C.) to attend a faculty meeting and invite instructors to participate in the study.

The researcher reviewed the purpose of the project and explained the consent form. The potential respondents were informed that, to maintain the confidentiality of their participation, the department chair and the researcher would leave the room while they did or did not complete the questionnaire. If they wished to participate, they were to return the completed questionnaire in the envelope provided; if they did not wish to participate, they were instructed to return the blank survey in the same envelope or not to return the survey at all. Participants were asked to recall the researcher and department chair to the room after the last person submitted a survey.

The university Institutional Review Board reviewed this project and designated it as exempt.

\section{Data Analysis}

We tested the model in Figure 1, using the steps that Baron and Kenny (1968) discuss as establishing mediation: 1) test the

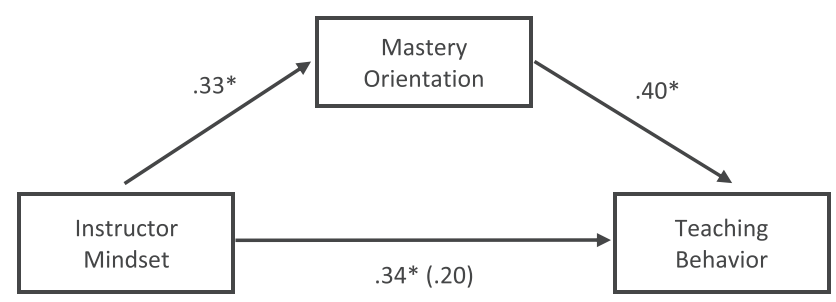

FIGURE 1. Standardized regression coefficients for the relationship between Instructor Mindset and Teaching Behavior as mediated by Mastery Orientation. The standardized regression coefficient between Instructor Mindset and Teaching Behavior, controlling for Mastery Orientation, is in parentheses. ${ }^{*} p<0.05$. 
TABLE 1. Regression: Instructor Mindset and Mastery Orientation predict teaching behavior

\begin{tabular}{lcccc}
\hline Predictors & B & SE B & B & p \\
\hline Instructor Mindset & 0.11 & 0.07 & 0.20 & 0.11 \\
Mastery Orientation & 0.52 & 0.16 & 0.40 & 0.002 \\
$R^{2}$ & 0.26 & & & \\
\hline
\end{tabular}

relationship between the outcome variable (Teaching Behavior) and the predictor (Instructor Mindset) to demonstrate that there is an effect to be mediated; 2) test the relationship between the predictor (Instructor Mindset) and the mediator (Mastery Orientation); and 3) test the relationship between the mediator (Mastery Orientation) and the outcome (Teaching Behavior) by conducting a regression analysis in which both predictor and mediator predict the outcome. Support for a mediated model is evidenced by significant relationships in steps 1 and 2 and a reduction in the effect of the predictor in step 3.

\section{RESULTS}

Respondents reported relatively high scores on all variables: Growth Mindset ( $\mathrm{M}=4.58, \mathrm{SD}=1.02$, range: $2.50-6.00)$; Mastery Orientation ( $\mathrm{M}=4.61, \mathrm{SD}=0.42$, range: $3.92-5.85)$; Teaching Behaviors ( $\mathrm{M}=4.39, \mathrm{SD}=0.54$, range: $3.30-5.36)$.

As predicted, the relationship between Instructor Mindset and Teaching Behaviors was mediated by Mastery Orientation (see Figure 1). Step 1 revealed a positive relationship between Instructor Mindset and Teaching Behavior (standardized beta $=$ $0.34, p=0.01$ ). Step 2 revealed a positive relationship between Instructor Mindset and Mastery Orientation (standardized beta $=0.33, p=0.01$ ). Step 3 revealed that Mastery Orientation significantly predicted Teaching Behaviors when controlling for the relationship with Instructor Mindset (standardized beta = $0.40, p=0.002$ ); this analysis also revealed a weaker (and nonsignificant) relationship between Instructor Mindset and Teaching Behaviors (standardized beta $=0.20, p=0.11$ ).

The final regression equation (see Table 1), in which both Instructor Mindset and Mastery Orientation predicted Teaching Behavior, can also be interpreted in terms of the relative ability of mindset and mastery orientation to predict evidence-based teaching practice. The final model revealed that Instructor Mindset is no longer a significant predictor of Teaching Behaviors when Mastery Orientation is taken into consideration. ${ }^{1}$

\section{DISCUSSION}

The primary focus of this study was the examination of the extent to which faculty beliefs about intelligence were related to their ideas about motivation and the extent to which those beliefs related to their adoption of evidence-based effective teaching practices. The results of this study support a mediated model of the relationship between instructor mindset and teaching practices in which that relationship depends upon the motivational effects of mindset. In sum, if instructors believe that ability is not fixed (i.e., that ability can grow), they are likely also to believe that their behavior can impact student

${ }^{1}$ The regression analyses included consideration of assumptions of multicollinearity, normality, linearity, and homoscedasticity, and in no case were those assumptions violated. outcomes (Mastery Orientation), which, in turn, predicts a likelihood that instructors will take responsibility for student learning and design and deliver course material so that it is accessible and motivating to students and includes opportunities for practice, reflection, and feedback.

As evidenced by the descriptive data, the STEM instructors in this study represented themselves as having a growth mindset. In fact, more than $75 \%$ of the respondents scored at least 4 on the six-point scale. They also believed strongly in the relationship between effort and learning success (i.e., mastery orientation). The relatively small SD for Mastery Orientation is supported by the limited range of scores; the lowest average score was 3.92 and $98 \%$ of respondents scored at least 4 on the six-point scale.

These results might be interpreted as supportive of the arguments in recent studies that have argued that "bold claims about mind-set appear to be overstated" (Burgoyne et al., 2020 , p. 258). We would argue that the mediated model is consistent with Dweck's theory of motivation, although it does not seem to support more recent variations on the theory that focus primarily on the mindset construct. Our findings, then, are not consistent with the recent emphasis on mindset as a direct contributor to outcomes, but they are supportive of the original, more nuanced version of the theory as described in the Introduction to this paper and by Dweck and colleagues (e.g., Dweck and Leggett, 1988). Indeed, mindset does matter. At least in the case of the present study, mindset does not matter so much as a direct effect on teaching behavior but as an indirect effect through motivation as conceptualized in terms of mastery orientation.

Our results are consistent with other research that has examined relationships between instructor attitudes and teaching and learning outcomes and may provide a deeper understanding of underlying mechanisms that account for those relationships. For example, Ferrare (2019) and Canning et al. (2019) linked instructor beliefs about teaching to their practices. More specifically, Rattan et al. (2012) and Aragon et al. (2018) found a relationship between instructor mindset and teaching practices. Our findings suggest that motivation and mastery orientation may account for that link between beliefs and practices.

\section{Limitations}

As noted by Reeves and Marbach-Ad (2016), "Rather than providing evidence of each 'type' of validity, the charge for test developers is to construct a cohesive argument for the validity of ... inferences that integrates different forms of validity evidence" (pp. 2-3). Although our measures of Mastery Orientation and Teaching Behaviors have not been subjected to full validity studies, we are able to present various forms of validity evidence. We provided some evidence of the validity of the measures in the Methods section, and the support for the predicted relationships provides additional evidence of the construct validity of the measures. However, there are some forms of validity evidence that we are not able to provide. For example, we have not conducted think-aloud procedures that would provide more evidence of response process validity, assuring that the respondents interpreted the items on the scales as we intended. In addition, the internal consistency of the measure of Mastery Orientation did not quite meet the 
standard for providing clear evidence of internal structure validity. Future research might address some of these concerns in full-blown validity studies of Teaching Behaviors and Mastery Orientation.

As noted earlier, this study is based on a relatively small sample of STEM instructors, all from one institution with departments that often have strong internal cultures that influence instructors' attitudes and expectations for teaching and learning. In addition, the findings of this study are entirely reliant on self-reported data and thus should be considered only a starting point for understanding the links among mindset theories, motivational orientation, and teaching practices. It is possible that the relationships among at least some of the variables could be accounted for by social desirability responding (i.e., desiring to appear good or knowledgeable). For example, efforts at faculty development throughout the university, and especially in the STEM disciplines, may have produced a group of faculty who at least know what is expected in terms of evidence-based teaching practices, and they know that the "right" mindset is a growth mindset and that students should be encouraged to exert effort (rather than rely on ability). Further investigation of teaching practices with more objective (e.g., observational) methods or differently biased methods (e.g., student reports) is called for.

Although we found support for Dweck's foundational theory among STEM faculty, we cannot generalize our findings to nonSTEM faculty. Further, we asked our faculty participants to respond with regard to a course that presented challenges to students. It is possible that instructors who teach especially challenging courses are especially inclined to reflect on teaching and learning and to consider how to encourage effort as a means of ensuring student success. Further research testing the theory among non-STEM instructors and for less challenging courses is called for.

\section{CONCLUSIONS}

This study points to the potential applicability of a psychological theory of motivation and personality to an understanding of instructor motivation that may stimulate or discourage effective teaching practices in STEM disciplines. Dweck's social cognitive model, which was developed to explain student motivation and learning behaviors, may also contribute to an understanding of instructor motivation and teaching behaviors.

On a basic level, this study develops a model that predicts the extent to which faculty beliefs about intelligence and motivation relate to their adoption of evidence-based teaching practices and seems to confirm the value of the implicit theories of self in predicting behavior. On a more speculative level, these findings suggest interventions that would encourage faculty to adopt evidence-based practices. Instead of emphasizing interventions that attempt to modify mindset, we might want to point colleagues to their own self-reflective practices in research and teaching and emphasize the value of actively cultivating similar qualities in their students. Canning et al. (2019) argue that making instructors aware of how their mindset is likely to impact student motivation and performance and helping them create mindset cultures in their classes would incur little to no cost. We suggest that the impact might be greater if we focus on encouraging faculty to target motivation and metacognitive self-reflection.

\section{REFERENCES}

American Educational Research Association, American Psychological Association, and National Council on Measurement in Education. (2014). Standards for educational and psychological testing. Washington, DC.

Aragon, O. R., Eddy, S. L., \& Graham, M. J. (2018). Faculty beliefs about intelligence are related to the adoption of active-learning practices. CBE-Life Sciences Education, 17(3), ar47. doi: 10.1187/cbe.17-05-0084

Baron, R. M., \& Kenny, D. A. (1986). The moderator-mediator variable distinction in social psychological research: Conceptual, strategic, and statistical considerations. Journal of Personality and Social Psychology, 51 1173-1182. doi: 10.1037/0022-3514.51.6.1173

Blackwell, L., Trzesniewski, K., \& Dweck, C. S. (2007). Implicit theories of intelligence predict achievement across an adolescent transition: A longitudinal study and an intervention. Child Development, 78, 246-263. doi: 10.1111/j.1467-8624.2007.00995.x

Burgoyne, A. P., Hambrick, D. Z., \& Macnamara, B. N. (2020). How firm are the foundations of mind-set theory? The claims appear stronger than the evidence. Psychological Science, 31, 258-267. doi: 10.1177/ 0956797619897588

Burnette, J. L., O'Boyle, E. H., VanEpps, E. M., Pollack, J. M., \& Finkel, E. J. (2013). Mind-sets matter: A meta-analytic review of implicit theories and self-regulation. Psychological Bulletin, 139, 655-701. doi: 10-10347/ a0029531

Canning, E. A., Muenks, K., Green, D. J., \& Murphy, M. C. (2019). STEM faculty who believe ability is fixed have larger racial achievement gaps and inspire less student motivation in their classes. Science Advances, 5(2), eaau4734. doi: $10.1126 /$ sciadv.aau4734

Cook, D. A., Gas, B. L., \& Artino, A. R. (2018). Measuring mindsets and achievement goal motivation: A validation study of three instruments. Academic Medicine, 93, 1391-1399. doi: 10.1097/ACM.0000000000002290

Downing, S. M. (2003). Validity: On the meaningful interpretation of assessment data. Medical Education, 37, 830-837. doi: 10.1046/ j.1365-2923.2003.01594.x

Dweck, C. S. (2000). Self-theories: Their role in motivation, personality, and development. New York: Psychology Press.

Dweck, C. S. (2006). Mindset: The new psychology of success. New York: Ballantine Books.

Dweck, C. S. (2008). Mindsets and math/science achievement. New York: Carnegie Corporation.

Dweck, C. S., \& Leggett, E. L. (1988). A social-cognitive approach to motivation and personality. Psychological Review, 95, 256-273. doi: 10.1037/ 0033-295X.95.2.256

Ferrare, J. J. (2019). A multi-institutional analysis of instructional beliefs and practices in gateway courses to the sciences. CBE-Life Sciences Education, 18(2), ar26. doi: 10.1187/cbe.17-12-0257

Furr, R. M. (2017). Psychometrics: An introduction. Thousand Oaks, CA: Sage.

Grant, H., \& Dweck, C. S. (2003). Clarifying achievement goals and their impact. Journal of Personality and Social Psychology, 85, 541-553. doi: 10.1037/0022-3514.85.3.541

Henson, R. K. (2001). Understanding internal consistency reliability estimates: A conceptual primer on coefficient alpha. Measurement and Evaluation in Counseling and Development, 34, 177-189. doi: 10.1080/ 07481756.2002 .12069034

Midgley, C., Maehr, M. L., Hruda, L. Z. et al. (2000). Manual for the patterns of adaptive learning scales. Ann Arbor: University of Michigan.

Paunesku, D., Walton, G. M., Romero, C., Smith, E. N., Yeager, D. S., \& Dweck, C. S. (2015). Mind-set interventions are a scalable treatment for academic underachievement. Psychological Science, 26, 784-793. doi: 10.1177/ 0956797615571017

Rattan, A., Good, C., \& Dweck, C. S. (2012). "It's ok-Not everyone can be good at math": Instructors with an entity theory comfort (and demotivate) students. Journal of Experimental Social Psychology, 48(3), 731737. doi: 10.1016/j.jesp.2011.12.012

Reeves, T. D., \& Marbach-Ad, G. (2016). Contemporary test validity in theory and practice: A primer for discipline-based education researchers. CBE-Life Sciences Education, 15(1), rm1. doi: 10.1187/ cbe.15-08-0183 
Sisk, V. F., Burgoyne, A. P., Sun, J., Butler, J. L., \& Macnamara, B. N. (2018) To what extent and under which circumstances are growth mind-sets important to academic achievement? Two meta-analyses. Psychological Science, 29(4), 549-571. doi: 10.1177/0956797617739704

Wieman, C., \& Gilbert, S. (2014). The Teaching Practices Inventory: A new tool for characterizing college and university teaching and mathematics and science. CBE-Life Sciences Education, 13, 552-569. doi: 10.1187/ cbe.14-02-0023
Woodbury, S., \& Gess-Newsome, J. (2002). Overcoming the paradox of change without difference: A model of change in the arena of fundamental school reform. Educational Policy, 16, 763-782. doi 10.1177/089590402237312

Yeager, D. S., Romero, C., Paunesku, D., Hulleman, C. S., Schneider, B., Hinojosa, C., ... Dweck, C. S. (2016). Using design thinking to improve psychological interventions: The case of growth mindset during the transition to high school. Journal of Educational Psychology, 108(3), 374. doi: 10.1037/edu0000098 